\title{
Comparative growth performance of fast-growing tree species for woodfuel production in highland area of Ethiopia
}

\begin{abstract}
Biomass fuel is the most important source of energy in Ethiopian highlands where the fuelwood demand is high. The objective of the study was to evaluate the performance of eleven tree species for fuelwood production in Diksis Woreda, Oromiya region of Ethiopia. Randomized Complete Block Design with three replications was employed for the purpose. Survival count, root collar diameter growth, height and Diameter at breast height measurements $(\mathrm{DBH})$ measured annually until six year since the time of planting. A one way ANOVA was performed and treatments separation were made by using Least Significance Difference (LSD) Fisher Tests $(\mathrm{P} \leq 0.05)$. Eucalyptus saligna showed maximum survival (98\%), followed by E. grandis (89\%), E. camaldulensis (87\%), E. globulus $(86 \%)$ and Acacia decurrens (83\%); while the lowest survival rate was recorded for Schinus molle (37\%). Most of the Eucalyptus species showed good growing performances both in height and in DBH. The highest average DBH growth registered for Eucalyptus saligna and the age-height graphs on the other hand indicate that Eucalyptus viminalis is the fastest growing in height followed by E. globulus and E. saligna respectively. The wood volume estimation six year after planting also showed significant differences among the six most selected species and E. globulus showed the highest significant overall mean stem volume, with the exceptional of $E$. saligna and $E$. viminalis. Thus, these species recommended for fuelwood plantations in the area. However, an ecological based study on the species effects in highlands recommended before using for large-scale fuelwood plantations.
\end{abstract}

Volume 2 Issue 6 - 2018

\author{
Tatek Dejenea,' Berhane Kidaneb, ${ }^{2}$ Tinsae \\ Bahirua,' Mihret Semerea,' Kibruyesfa \\ Sisaya,' Eguale Tadessea' \\ 'Central Ethiopia Environment and Forestry Research Center, \\ Ethiopia \\ ${ }^{2}$ Ethiopian Environment and Forest Research Institute, Ethiopia
}

Correspondence: Tatek Dejene Bekele, Central Ethiopia Environment and Forestry Research Center. P.O. Box 30708, Addis Ababa, Ethiopia, Tel +251911910829,

Email tdezenie@yahoo.com

Received: October 04, 2018 | Published: November 16, 2018

Keywords: fuelwood, highland, fast growing species, plantation, diksis, Ethiopia

\section{Introduction}

Biomass fuel is the most important source of energy in developing countries and the status of fuel wood consumption in these countries reviewed. ${ }^{1}$ The review recognized that large number of people depended on fuelwood that led to depletion of the natural forest resources, with serious negative livelihood consequences for the rural poor in developing countries. ${ }^{1}$ Wood fuel is principally traditional, but could not phase out from being major source of household energy for various purposes. ${ }^{2}$ However, the fuel wood shortage propounded based largely on looking at supply and demand from the natural forest resources. ${ }^{3,4}$ Deforestation was also seen as one consequence as the consumption exceeded annual forest growth rates. Furthermore, this problem is often being aggravated by population growth. ${ }^{3}$

Ethiopia has been facing rapid deforestation and degradation of forest lands (Badege). The natural forest cover of the country has declined considerably in the last decades (Kuru). The change in natural forest cover is estimated between 150,000 and 200,000 ha (ha) of land per year (Zewdie). Today, the area covered with the natural forest is less than $3 \%$ of the country's total lands (Lemenih \& Taddese). Increasing demands for fuelwood is among the major causes for such changes in Ethiopia. ${ }^{5-8}$ In spite of this, recently, the pattern of fuelwood consumption is improved by householders' tree plantations, where natural forests are scarce (Bewket). As a consequence, tree planting has emerged as a plausible option to fulfill the fuelwood demand in the country ${ }^{9}$ and is also becoming a key environmental issue $^{10}$ as a means for the rehabilitation of degraded lands (Jaleta). Hence, plantation of fast-growing trees has become a major forestry practice, thereby reducing pressure on the natural forest resources (Bekele \& Zewdie). However, the plantations are dominated by few tree species (Bekele \& Moges) as they are preferred owing to their growth nature, coppicing ability and wider adaptation to different ecological conditions. ${ }^{2}$

The high altitude areas of Ethiopia encounter a multitude of problems such as limited tree species. ${ }^{11}$ Relying heavily on few species has risks and impacts on the productivity and sustainability of the forest farming systems, particularly in the highland area of the country. Thus, a wider range of tree species would ensure resilience and decrease sensitivity to pests and diseases. ${ }^{12}$ The past attempts in Ethiopia to reforest and restore degraded forests and thereby fulfill the woodfuel requirements in the rural area of the country relied on screening of multipurpose tree species in some agro-ecological zones. ${ }^{12}$ However, the output from such trials did not reach many areas of the farming communities over the country. Thus, selection and promotion of fast growing species that fit the farming system is one of the strategies for improving the woodfuel availabilities and thereby reducing pressure on the remaining natural forest. In view of this, a research was undertaken on selection of trees for woodfuel purpose in the highland part of the country. The general objectives of the study was, therefore to select better performed fast growing and high biomass producing tree species for woodfuel production purpose in the study area. 


\section{Materials and methods}

\section{Study site description}

The study was conducted from 2013 to 2018 at Diksis Woreda of the Arsi Zone in Oromia Region of Ethiopia (Figure 1). The study site was located between $39^{\circ} 30^{\prime}$ to $39^{\circ} 40^{\prime} \mathrm{E}$ Latitude and $8^{\circ} 10^{\prime}$ to $7^{\circ} 55^{\prime}$ $\mathrm{N}$ Longitude. Mean annual maximum and minimum temperatures are 23 and $6{ }^{\circ} \mathrm{C}$ respectively. The mean annual precipitation is 1100 $\mathrm{mm}$, most falling between March and October with peaks in July and August. The soil of the study area is classified as Nitosols.

The experimental site was selected through a participatory process with the local people and further discussion was also done with district agricultural experts and development agents of the study area. Then, accessibility and representativeness were taken as basis for selection of the study area. Prior to 2013, the selected site was grazing area and without vegetation cover.

\section{Criteria for species selection and tree seed sources}

Farmers were consulted with their priority needs with regard to woodfuel in the study area. They responded that they preferred fast growing trees that easily adapted to their area and produce high biomass for fuel. Then, we took trees for our selection purpose based on the suggestion from database of the International Center for Research in Agroforesty (ICRAF) and their presence in the same agroecological zones of the study area. Seeds of the selected tree species (Table 1) were collected from the Central Ethiopia Environmental and Forestry Research Center (CEE-FRC). Appropriate seed treatments were applied whenever necessary, for example, seeds of $A$. decurrens were immersed in boiling water and cooled for 24 hours, seeds of Acacia mearninsii boiled in water for a minute at $100^{\circ} \mathrm{C}$ to induce germination. Then, treated seeds were directly sown in polythene bags that contained a mixture 4 (local soil): 2 (forest soil): 1 (sand) followed Kindu et al. ${ }^{12}$ Polythene bag size was $15 \mathrm{~cm}$ and $8 \mathrm{~cm}$ in height and diameter respectively.

\section{Experimental design and management}

Seedlings were raised in Melkasa Agricultural Research Center (MARC) nursery site, the nearby nursery to the study area. Then, field preparation began one week before planting. Planting holes were dug $40 \mathrm{~cm}$ deep at Diksis. The size of the plot was $7.5 \times 7.5 \mathrm{~m}$. A plot consisted of six rows of trees that had a line of six trees. One plots had a total of 36 seedlings. Distance between trees in the same row was $1.5 \mathrm{~m}$ while distance between rows in the same plot was $1.5 \mathrm{~m}$. The distance between plots was $2 \mathrm{~m}$ and distance between blocks was $3 \mathrm{~m}$. Treatments (seedlings of each species in Table 1) were laid out in a Randomized Complete Block Design (RCBD) with three replications. ${ }^{13}$ Weeding and hoeing were applied after planting uniformly two times in a year to the entire plot in the first and second year of the growing period.

\section{Data analysis}

Tree data such as Root Collar Diameter (RCD), Diameter at Breast Height (DBH), height and steam volume were subjected to one way ANOVA analysis and means were compared by Least Significance Difference (LSD) Fisher Tests ( $\mathrm{P} \leq 0.05)$. STATISTICA '08 Edition software (StatSoft Inc., 1984-2008) was used for the analysis. Moreover, survival of each species analyzed. Heteroscedasticity was treated by logarithmic transformation for root collar diameter, $\mathrm{DBH}$, height and volume increments data. The transformation were done using the excel spreadsheet. DBH-age and height- age curves generated for each of the species at the various ages to see the strength of correlation coefficients of the variables.

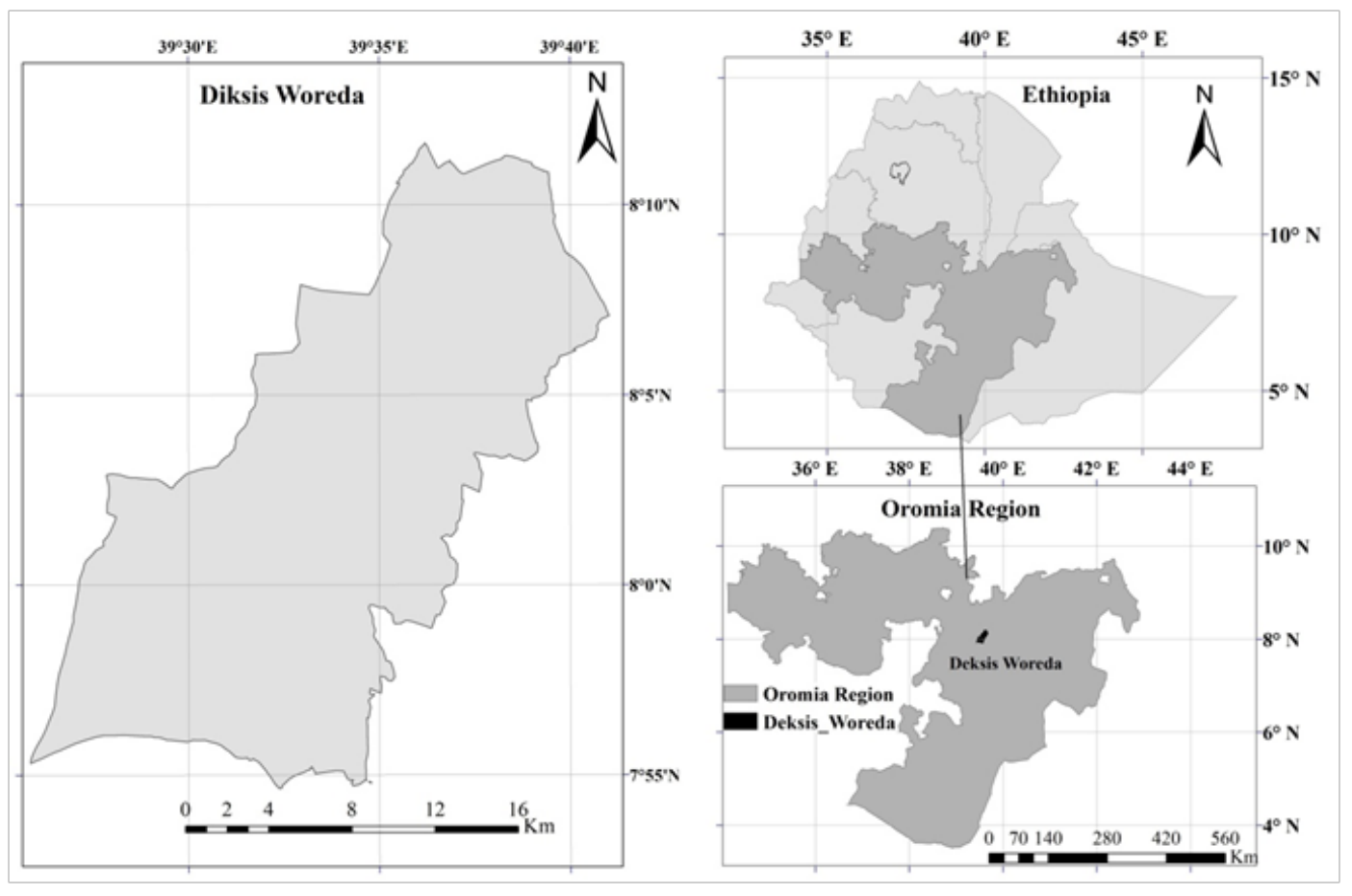

Figure I Map of Ethiopia and Oromia Nations state, showing the location of Diksis, the study area. 
Table I Scientific and family names as well as seed sources of eleven tested tree species for woodfuel

\begin{tabular}{llll}
\hline Species & Family & Common name & Treatments \\
\hline Acacia decurrens & Fabaceae & Black wattle & Hot water \\
Acacia melanoxylon & Fabaceae & Australian blackwood & Hot water \\
Casuarina equesitifolia & Casuarinaceae & Australian pine tree & No treatment \\
Cupresus lusitanica & Cupressaceae & Mexican white cedar & No treatment \\
Eucalyptus camaldulensis & Myrtaceae & River red gum & No treatment \\
Eucalyptus globulus & Myrtaceae & Tasmanian bluegum & No treatment \\
Eucalyptus grandis & Myrtaceae & Flooded gum & No treatment \\
Eucalyptus saligna & Myrtaceae & Sydney blue gum & No treatment \\
Eucalyptus viminalis & Myrtaceae & The manna gum & No treatment \\
Gravelia robusta & Proteaceae & Silkoak & No treatment \\
Schinus molle & Anacardiaceae & Peruvian pepper & No treatment \\
\hline
\end{tabular}

\section{Results}

\section{Planted species survival}

The survival rate was generally good, being greater than $50 \%$ for most of the tree species in the study area. Survival count was made in the third measurement season, 36 months after out-planting, and was constant when each tree was compared at $>36$ months of growing periods. The highest survival was registered for Eucalyptus saligna (98\%) followed by Eucalyptus grandis (89\%), Eucalyptus camaldulensis (87\%), Eucalyptus globulus (86\%) and Acacia decurrens $(83 \%)$. Lower survival rates registered for Eucalyptus viminalis (68\%), Cupresus lusitanica (58\%), Gravelia robusta (49\%), Casuarina equesitifolia (47\%), Acacia melanoxylon (43\%) and Schinus molle (37\%). Of the total species, Acacia decurrens, Eucalyptus camaldulensis, Eucalyptus globulus, Eucalyptus grandis, Eucalyptus saligna, and Eucalyptus viminalis are used for further analysis.

\section{Root collar diameter (RCD) growth}

RCD measurements made consecutively for three years to all the planted trees. One year after planting the analysis revealed that no significant difference between trees $(\mathrm{F}=1.33, p=0.272)$. However, in this growing period, the highest RCD value found for Gravelia robusta followed by Schinus molle (Figure 2). However, in the second $(\mathrm{F}=5.71, p=0.0003)$ and third year $(\mathrm{F}=5.47, p=0.0004)$ of growing periods, we found significant differences in RCD growths between species. Eucalyptus viminalis and Cupresus lusitanica showed higher significant values in the second growing period (Table 2).

Unlike the first and second years, E. saligna, E. globulus, E. camaldulensis, E. viminalis and E. grandis respectively showed higher significant RCD values at the third growing period (Table 2). Generally RCD growth for all the trees showed an increasing trend and no-significant differences along the growing periods are provided (Table 2).

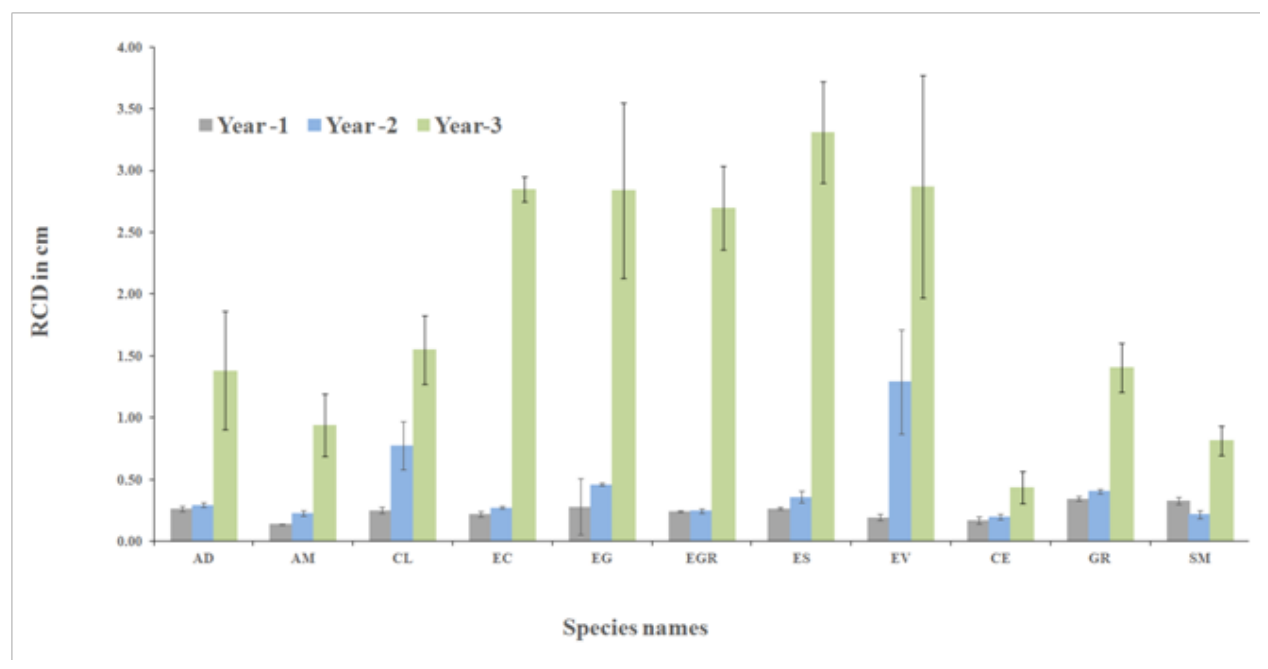

Figure 2 Comparison of mean Root Collar Diameter (RCD) for evaluated eleven species in the study area. The data are mean results (in $\mathrm{cm}$ ) \pm standard error of the mean. AD, Acacia decurrens; AM, Acacia melanoxylon; CL, Cupresus lusitanica; EC, Eucalyptus camaldulensis; EG, Eucalyptus globules; EGR, Eucalyptus grandis; ES, Eucalyptus saligna; EV, Eucalyptus viminalis; CE, Casuarina equesitifolia; GR, Gravelia robusta; SM, Schinus molle. 
Table 2 Differences of least squares means for Root Collar Diameter (RCD) and statistical significance for compared species along the three growing periods according to Fisher Tests

\begin{tabular}{|c|c|c|c|c|c|c|c|}
\hline \multirow{3}{*}{ Species } & \multicolumn{3}{|c|}{ Year since planting } & \multirow{3}{*}{ Species } & \multicolumn{3}{|c|}{ Year since planting } \\
\hline & Year-I & Year -2 & Year -3 & & Year - I & Year -2 & Year- 3 \\
\hline & $p$-values & p-values & $p$-values & & $p$-values & $p$-values & $p$-values \\
\hline AD-AM & 0.7338 & 0.4438 & 0.4780 & EC-EGR & 0.8484 & 0.9034 & 0.8011 \\
\hline$A D-C L$ & 0.9173 & 0.0253 & 0.7891 & EC-ES & 0.6432 & 0.6659 & 0.4622 \\
\hline$A D-E C$ & 0.6766 & 0.9110 & 0.0249 & EC-EV & 0.8024 & $<0.0000$ & 0.9779 \\
\hline$A D-E G$ & 0.0581 & 0.9310 & 0.0260 & EC-CE & $0.627 \mid$ & 0.7037 & $<0.0007$ \\
\hline AD-EGR & 0.8207 & 0.8158 & 0.0426 & EC-GR & 0.2285 & 0.5190 & 0.0270 \\
\hline AD-ES & 0.9630 & 0.7485 & 0.0046 & EC-SM & 0.2949 & 0.7837 & 0.0030 \\
\hline AD-EV & 0.5061 & $<0.0001$ & 0.0234 & EG-EGR & 0.0464 & 0.8835 & 0.8162 \\
\hline$A D-C E$ & 0.3699 & 0.6232 & 0.1373 & EG-ES & 0.0637 & 0.6842 & 0.4506 \\
\hline$A D-G R$ & 0.4233 & 0.5930 & 0.9701 & EG-EV & 0.0138 & $<0.0000$ & 0.9623 \\
\hline AD-SM & 0.5223 & 0.6996 & 0.3632 & EG-CE & 0.0080 & 0.6852 & 0.0007 \\
\hline $\mathrm{AM}-\mathrm{Cl}$ & 0.8130 & 0.0043 & 0.3317 & EG-GR & 0.2493 & 0.5352 & 0.0282 \\
\hline AM-EC & 0.9383 & 0.5118 & 0.0049 & EG-SM & 0.1910 & 0.7645 & 0.0031 \\
\hline AM-EG & 0.0285 & 0.4960 & $0.005 I$ & EGR-ES & 0.7849 & 0.5809 & 0.3266 \\
\hline AM-EGR & 0.9094 & 0.5918 & 0.0088 & EGR-EV & 0.6595 & $<0.0000$ & 0.7798 \\
\hline AM-ES & 0.6993 & 0.2813 & $<0.0001$ & EGR-CE & 0.4998 & 0.7953 & 0.0013 \\
\hline AM-EV & 0.7434 & $<0.0000$ & 0.0046 & EGR-GR & 0.3072 & 0.4448 & 0.0460 \\
\hline AM-CE & 0.5738 & 0.7809 & 0.4208 & EGR-SM & 0.3886 & $0.878 I$ & 0.0055 \\
\hline$A M-G R$ & 0.2583 & 0.1997 & 0.4555 & ES-EV & 0.4773 & $<0.0001$ & 0.4790 \\
\hline AM-SM & 0.3307 & 0.7010 & 0.8381 & ES-CE & 0.3463 & 0.4193 & $<0.0001$ \\
\hline CL-EC & 0.7537 & 0.0198 & 0.0440 & ES-GR & 0.4501 & 0.8297 & 0.0050 \\
\hline CL-EG & 0.0570 & 0.0209 & 0.0458 & ES-SM & 0.5525 & 0.4818 & 0.0005 \\
\hline CL-EGR & 0.9022 & 0.0151 & 0.0732 & EV-CE & 0.8130 & $<0.0000$ & $<0.0006$ \\
\hline CL-ES & 0.8806 & 0.0498 & 0.0086 & EV-GR & 0.1499 & $<0.0002$ & 0.0254 \\
\hline CL-EV & 0.5738 & 0.0174 & 0.0415 & EV-SM & 0.1984 & $<0.0000$ & 0.0028 \\
\hline CL-CE & 0.4264 & 0.0083 & 0.0835 & CE-GR & 0.0974 & 0.3093 & 0.1284 \\
\hline CL-GR & $0.367 \mid$ & 0.0766 & 0.8181 & CE-SM & 0.1317 & 0.9154 & 0.5458 \\
\hline CL-SM & 0.4582 & 0.0106 & 0.2432 & GR-SM & 0.8699 & 0.3608 & 0.3443 \\
\hline EC-EG & $0.024 I$ & 0.9799 & 0.9844 & & & & \\
\hline
\end{tabular}

Note in bold: significant differences among species at $95 \%$ of confidence $A D$, Acacia decurrens; AM, Acacia melanoxylon; CL, Cupresus lusitanica; EC, Eucalyptus camaldulensis; EG, Eucalyptus globules; EGR, Eucalyptus grandis; ES, Eucalyptus saligna; EV, Eucalyptus viminalis; CE, Casuarina equesitifolia; GR, Gravelia robusta; SM, Schinus molle 


\section{Species growth performance}

Diameter growth measurements were taken only for the most six survived species. The growth of each of the species generally followed an increasing pathway (Figure 3). The age DBH curves of the species show that apart from Eucalyptus viminalis, which has relatively low correlation coefficient $\left(\mathrm{R}^{2}=0.8247\right)$, there is a very strong correlation $\left(\mathrm{R}^{2}>90 \%\right)$ between age and DBH growth for the other species.

Analysis of DBH data showed a significant difference among the species along the growing periods $(p<0.05)$, with the exception of the first year (Table 3). Most of the Eucalyptus species showed good growing performances, ranging from 3 to $6 \mathrm{~cm}$ in DBH. The highest average DBH growth registered for Eucalyptus saligna $(6 \mathrm{~cm})$ followed by E. globulus $(5.57 \mathrm{~cm})$, E. viminalis $(4.64 \mathrm{~cm}), E$. grandis $(4.20 \mathrm{~cm})$ and E. camaldulensis $(3.58 \mathrm{~cm})$ after six years of growing period. The lower DBH value registered for Acacia decurrens $(3.45$ $\mathrm{cm})$. Resulted DBH significant differences along the growing periods are provided (Table 3). The age-height graphs on the other hand indicate that Eucalyptus viminalis is the fastest growing in height followed by E. globulus and E. saligna respectively. Eucalyptus camaldulensis showed the lowest height growth (Figure 4). However, all the six species showed strong correlationof age and height $\left(\mathrm{R}^{2}=\right.$ $80 \%$ ) along the growing periods (Figure 4 ). Analysis of annual height data showed a significant difference among the treatments $(p<.05)$. at the age of six year, the highest average height growth was found for Eucalyptus globulus $(7 \mathrm{~m})$ followed by $E$. viminalis $(6.8 \mathrm{~m})$, E. saligna $(6.5 \mathrm{~m})$, A. decurrens $(5.7 \mathrm{~m})$ and $E$. grandis $(5.58)$. The lowest was for Eucalyptus camaldulensis $(4.9 \mathrm{~m})$ at six months after planting. Resulted height significant and non-significant differences along the growing periods are provided (Table 4).

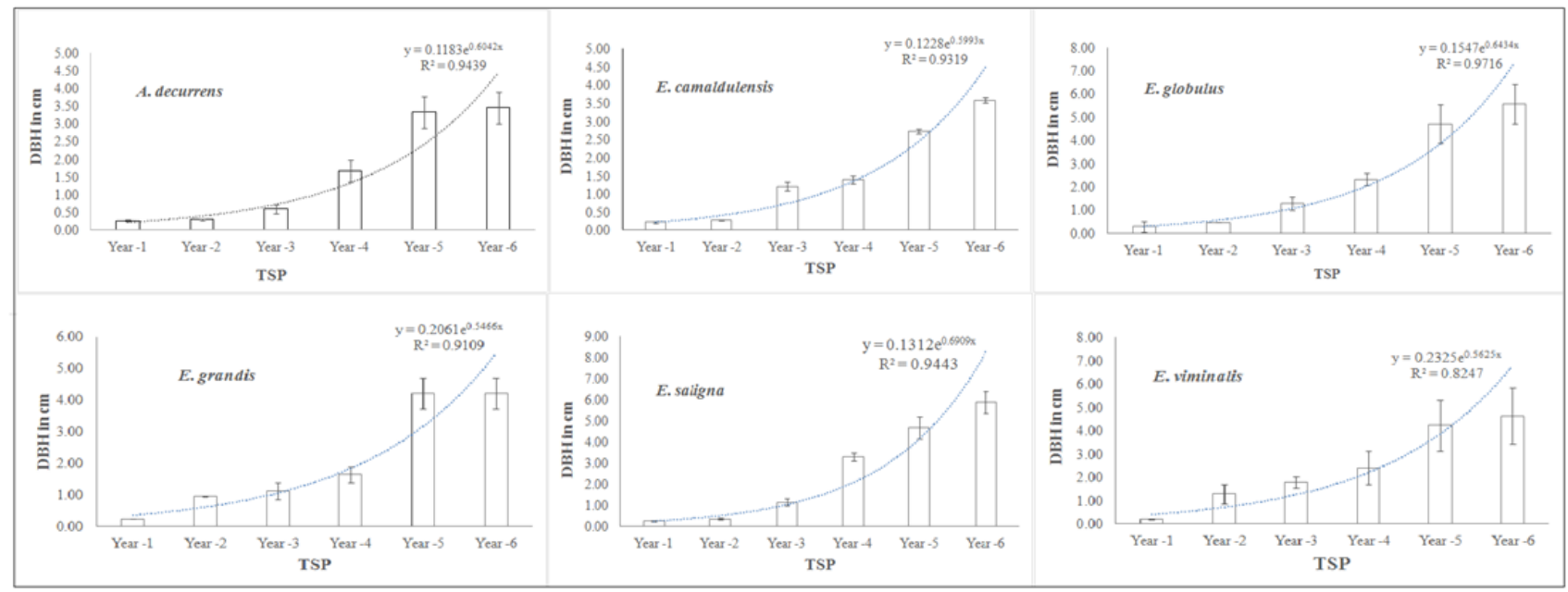

Figure 3 Age and $\mathrm{DBH}(\mathrm{cm})$ growth curves for evaluated seven species in the study area.The data are mean results \pm standard error of the mean. Equation on chart, the linear curve of the graph; $\mathrm{R}^{2}$, correlation coefficient;TSP,Time since planting.

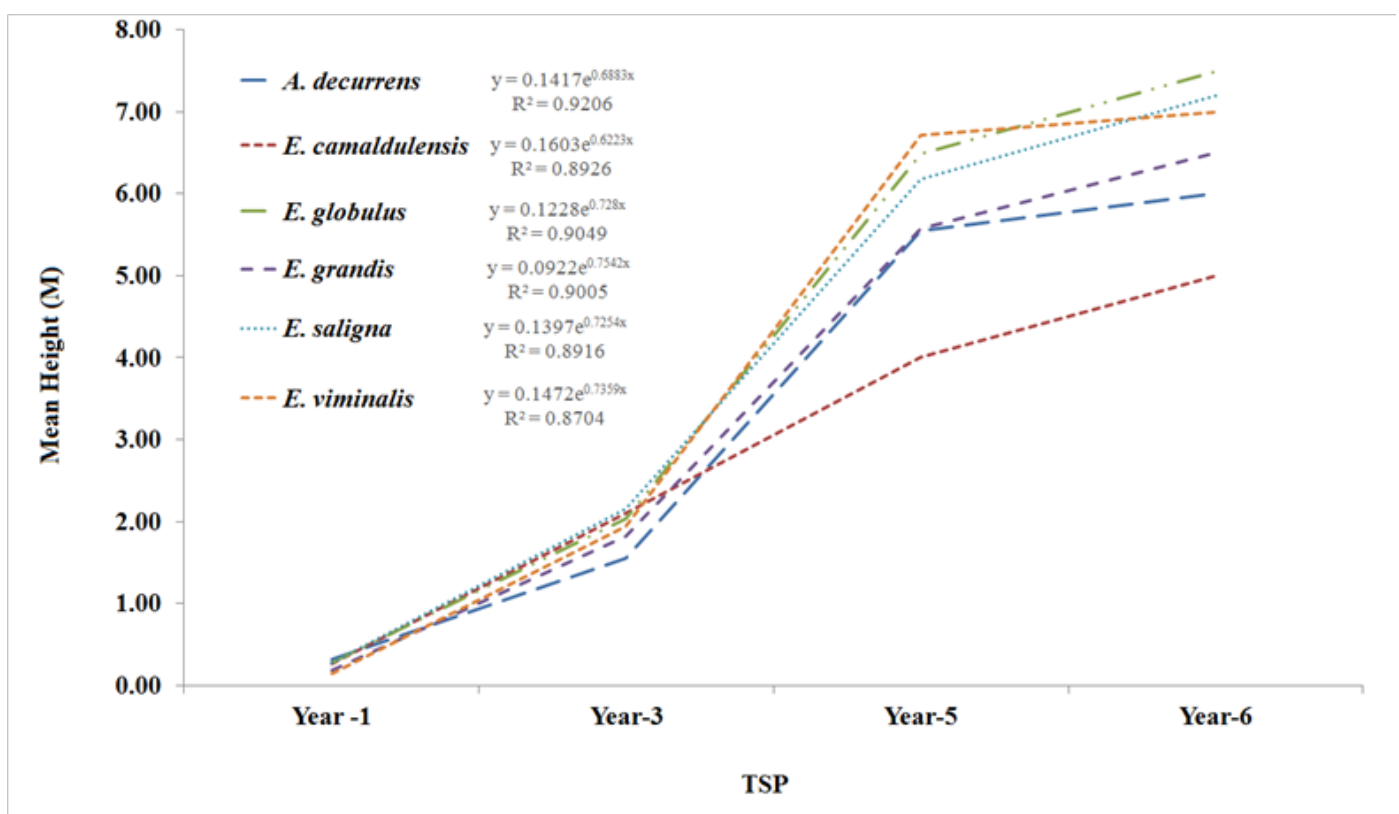

Figure 4 Age and height $(\mathrm{m})$ growth curves for evaluated six species in the study area. Equation on chart, the linear curve of the graph; $\mathrm{R}^{2}$, correlation coefficient ;TSP,Time since planting. 
Table 3 Differences of least squares means for Diameter at Breast Height (DBH) and statistical significance for compared species along the growing periods according to Fisher Tests

\begin{tabular}{|c|c|c|c|c|c|c|}
\hline \multirow{3}{*}{ Species } & \multicolumn{6}{|c|}{ Year since planting } \\
\hline & Year-I & Year -2 & Year -3 & Year -4 & Year -5 & Year -6 \\
\hline & p-values & $p$-values & $p$-values & $p$-values & $p$-values & $p$-values \\
\hline AD-EC & 0.9998 & $\mathrm{I} .0000$ & 0.0410 & 0.3580 & 0.5214 & 0.8856 \\
\hline AD-EG & 0.6723 & 1.0000 & 0.0208 & 0.4605 & 0.1420 & 0.0352 \\
\hline AD-EGR & 1.0000 & 1.0000 & 0.0763 & 0.2756 & 0.3444 & 0.4249 \\
\hline AD-ES & 1.0000 & 1.0000 & 0.0586 & 0.0059 & 0.1486 & 0.0180 \\
\hline AD-EV & 0.9974 & 0.0178 & 0.4762 & 0.1653 & 0.3274 & 0.2130 \\
\hline EC-EG & 0.4749 & 1.0000 & 0.7301 & 0.8508 & 0.0439 & 0.0464 \\
\hline EC-EGR & 1.0000 & 1.0000 & 0.7408 & 0.8566 & 0.1241 & 0.5104 \\
\hline EC-ES & 0.9997 & 0.9998 & 0.8506 & $<0.0001$ & 0.0462 & 0.0239 \\
\hline EC-EV & 1.0000 & 0.0151 & 0.1510 & 0.0300 & 0.1166 & $0.266 I$ \\
\hline EG-EGR & 0.5640 & 1.0000 & 0.5018 & 0.7128 & 0.5726 & 0.1533 \\
\hline EG-ES & 0.6941 & 0.9999 & 0.5950 & 0.0013 & 0.9785 & 0.7337 \\
\hline EG-EV & 0.3680 & 0.0157 & 0.0824 & 0.0432 & 0.5967 & 0.3219 \\
\hline EGR-ES & 1.0000 & 0.9992 & 0.8864 & $<0.0001$ & 0.5908 & 0.0845 \\
\hline EGR-EV & 0.9998 & 0.0127 & 0.2570 & 0.0210 & 0.9715 & 0.6366 \\
\hline ES-EV & 0.9963 & 0.0285 & 0.2057 & 0.0972 & 0.6153 & 0.1910 \\
\hline
\end{tabular}

Note In bold: significant differences among species at $95 \%$ of confidence AD, Acacia decurrens; EC, Eucalyptus camaldulensis; EG, Eucalyptus globules; EGR, Eucalyptus grandis; ES, Eucalyptus saligna; EV, Eucalyptus viminalis

Table 4 Differences of least squares means for height $(\mathrm{m})$ and statistical significance for compared species along the growing periods according to Fisher Tests

\begin{tabular}{|c|c|c|c|c|c|c|}
\hline \multirow{3}{*}{ Species } & \multicolumn{6}{|c|}{ Year since planting } \\
\hline & Year-I & Year -2 & Year -3 & Year -4 & Year -5 & Year -6 \\
\hline & $p$-values & p-values & $p$-values & $p$-values & $p$-values & $p$-values \\
\hline AD-EC & 0.0246 & 0.1588 & 0.1348 & 0.0364 & 0.1698 & 0.1417 \\
\hline$A D-E G$ & 0.0644 & 0.7596 & 0.1882 & 0.0260 & 0.2422 & 0.2852 \\
\hline AD-EGR & $<0.0000$ & 0.1366 & 0.4536 & 0.0093 & 0.9808 & 0.9433 \\
\hline$A D-E S$ & 0.0711 & 0.5925 & 0.1066 & 0.0592 & 0.5906 & 0.3879 \\
\hline AD-EV & $<0.0000$ & $<0.0000$ & 0.2743 & 0.0206 & 0.2922 & 0.3346 \\
\hline EC-EG & 0.6041 & 0.0945 & 0.8385 & 0.8562 & 0.0196 & 0.0196 \\
\hline EC-EGR & 0.0023 & 0.0092 & 0.4232 & 0.4750 & 0.1633 & 0.1594 \\
\hline EC-ES & 0.5665 & 0.3596 & 0.8905 & 0.0008 & 0.0671 & 0.0296 \\
\hline EC-EV & $<0.0001$ & $<0.0000$ & 0.6550 & $<0.0003$ & 0.0249 & 0.0242 \\
\hline EG-EGR & $<0.0001$ & 0.2240 & 0.5462 & 0.5909 & 0.2512 & 0.2566 \\
\hline EG-ES & 0.9556 & $0.405 I$ & 0.7332 & $<0.0006$ & 0.5110 & 0.8277 \\
\hline EG-EV & $<0.0000$ & $<0.0000$ & 0.8069 & $<0.0002$ & 0.8999 & 0.9118 \\
\hline EGR-ES & 0.0008 & 0.0531 & 0.3513 & $<0.0002$ & 0.6070 & 0.3519 \\
\hline EGR-EV & 0.0535 & $<0.0000$ & $0.7|7|$ & $<0.0001$ & 0.3026 & 0.3023 \\
\hline ES-EV & $<0.0000$ & $<0.0000$ & 0.5604 & 0.5715 & 0.5932 & 0.9148 \\
\hline
\end{tabular}

Note in bold: significant differences among species at $95 \%$ of confidence AD, Acacia decurrens; EC, Eucalyptus camaldulensis; EG, Eucalyptus globules; EGR, Eucalyptus grandis; ES, Eucalyptus saligna; EV, Eucalyptus viminalis 


\section{Steam volume}

Volume estimation was done six year after planting. We found significant differences among the six species in volume increment $(\mathrm{F}=38.21 ; \mathrm{P}<.0001)$. Eucalyptus globulus showed the higher significant $(\mathrm{P}<0.05)$ overall mean stem volume six year after planting, with the exceptional of E. saligna and E. viminalis (Figure 5). The lowest mean stem volume was obtained for E. camaldulensis. Although, there were numerical differences among E. camaldulensis, $A$. decurrensand $E$. grandis, the difference was not statistically significant $(\mathrm{P}>0.05$; Figure 5).

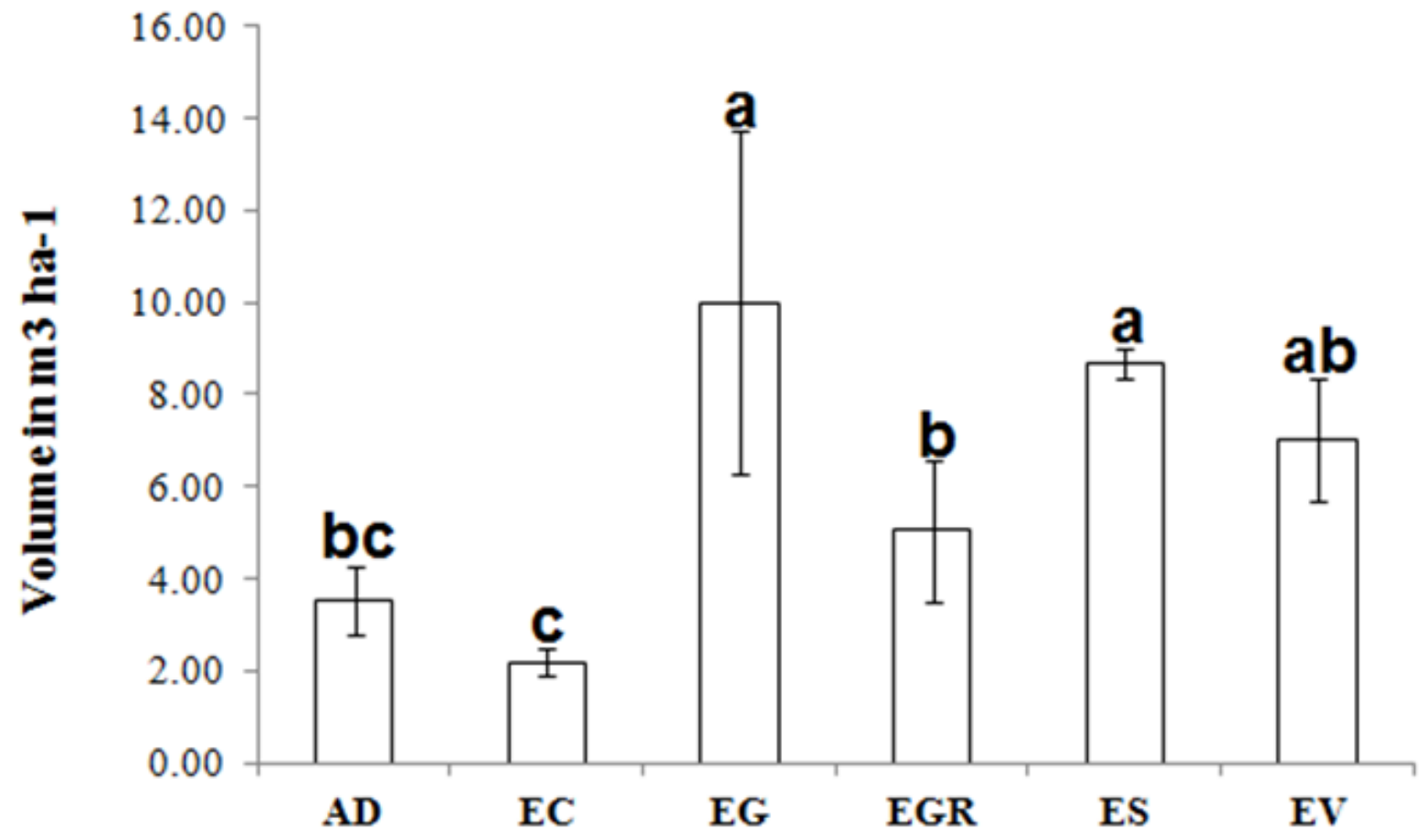

\section{Tree species name}

Figure 5 Comparison of mean volume $\left(\mathrm{cm}^{3}\right)$ for the six tree species evaluated for woodfuel in the study area. The data are mean results \pm standard error of the mean. Values with the same letter are not significantly different $(P<0.05)$.AD, Acacia decurrens; EC, Eucalyptus camaldulensis; EG, Eucalyptus globules; EGR, Eucalyptus grandis; ES, Eucalyptus saligna; EV, Eucalyptus viminalis.

\section{Discussion}

Wood energy dependence on natural forests has traditionally seen as a major cause of deforestation in developing countries, ${ }^{14}$ although it has been argued that fuelwood collection impacts can be mitigated through management practices. ${ }^{15}$ Plantation can play a major role in the rehabilitation of the forests ${ }^{16}$ and reduce the pressure on the natural forests as of the woodfuel requirement. This is true in Ethiopia that fuelwood shortage is leading to deforestation. ${ }^{17}$ In this regard, fast growing species considered as corridors to prevent deforestation in natural forests as well as provide fuelwood for local population (Lemenih and Bongers).

In the present study, selection of fast growing tree species conducted in highland part of Ethiopia, where fuel wood shortage is a common problem. Of the eleven tree species used, only six have shown good survival rates. All Eucalyptus species and A. decurrens had higher survival rates while the lower survival rates recorded for Gravelia robusta, Cupresus lusitanica, Acacia melanoxylon and Schinus molle treespecies. In line with our findings, Mekonnen et al. ${ }^{18}$ Tesfay et al. also reported high survival rate of Eucalyptus tree species in the highland area of Ethiopia. The lower survival of Gravelia robusta is unfortunate while it is reported $100 \%$ survival rate on a rainforest tree plantation after 6 years. ${ }^{19}$ Interestingly, A. decurrens showed higher survival while Tesfaye et al. reported the least survived in central highland part of Ethiopia. This might be due to the specific site condition or other environmental variable that make such differences in the survival of this particular species. On the contrary, in our study also Acacia melanoxylon had the least survival. In line with our result in Chile highlands areas reported a survival rate of less than $25 \%$ for Acacia species ${ }^{20}$ this might be because the species is less adaptable to extreme highland areas.

The result of this study also presents a selection of tree species for use as fuelwood production in the Central Highlands of Ethiopia.The mean volume production after six years in combination with mean height, root collar diameter growth (RCD), and diameter at breast height $(\mathrm{DBH})$ provides indicator ofthe species suitability for our objectives. The most rapidly growing species produced the greatest mean stem volume. For example, Eucalyptus globulus, E. salignaand E. viminalishad fasterroot collar diameter, DBH and height growth than other species. Of these species, Kindu et al. and Tesfaye et al. 2014 also reported E. globulus had greater height, RCD and DBH growth comparedwith other species in two different highland areas 
of Ethiopian. However, these did not hold true for some trees when compared with the other, where treesshowed good performance (Table 4). Although Acacia decurrens and E. camaldulensis showed the higher good survival rate, its height, RCD and DBH growth was intermediate that had impact on the final volume of wood production in the study area. Thus, the conditions can beimproved with the management practices or site condition so that the species recommendedfor widerplantation together with other good performed tree species. ${ }^{21,22}$

\section{Conclusion}

This study gives insight about the performance of different species for plantations with good management objectives. we recommend Eucalyptus globulus, E. salignaand E. viminalis for fuel wood production purpose based on their growing nature.Thus, foresters and landowners who wants to establish plantations of fast growing tree species for fuel use can use the results, it can be directly use at Diksis and other similar areas with similar climate, and growing sites conditions. However, the results should be regarded as a preliminary indication, and ecological based study on the species effects in highlands recommended before using them for large-scale fuelwood plantations. Other factors like site-specific problems, harvesting, insect, and disease control also needs more works before using the selected species

\section{Acknowledgements}

None.

\section{Conflict of interest}

Author declares that there is no conflict of interest.

\section{References}

1. Arnold J, Köhlin EM, Persson G, et al. Fuelwoods, Livelihoods, and policy interventions: changing perspectives. World Development 2015;34(3):596-611.

2. FAO. The global outlook for future wood supplies from forest plantations. IN: C Brown. editor. Italy; 2000:129.

3. Leach G, Mearus R. Beyond the woodfuel crisis: people, land and trees in Africa. Earthscan, London; 1988: 189-196.

4. Mather AS. Global Forest Resources. Timber Press, London, GB, 1990:341.

5. Pohjonen V, Pukkala T. Profitability of establishing Eucalyptus globulus plantations on central highland of Ethiopia. Silva Fennica. 1998;22:307-321.

6. Pohjonen V. Establishment of fuelwood plantations in Ethiopia. Joensuu University. Joensuu, Finland; 1989;388.
7. Pukkala T, Pohjonen V. Yield model for eucalyptus globulus fuelwood plantations in Ethiopia. Biomass. 1990;21(2):129-143.

8. Mekonenen A. Rural energy and afforestation: case studies from ethiopia, doctoral thesis. department of economics, Göteborg University. Göteborg, Sweden. 1988;135.

9. Lemenih M, Bongers F. The role of plantation forests in fosteringecological restoration: experience form East Africa. In degraded forestsin eastern Africa. Management and restoration. In: Bongers F, Tennigkeit T. editors. Earthscan Ltd: London; 2010;370.

10. Tesfaye MA, Bravo OA, Bravo F, et al. Selection of tree species and soil management for simultaneous fuelwood production and soil rehabilitation in the Ethiopian central highlands. Land Degrad. 2014.

11. German LA, Berhane K, Kindu M. Watershed management to counter far ming systems decline: toward a demand-driven, systems-oriented research agenda. Agricultural Research \& Extension Network Paper. $2005 ; 145$.

12. Kindu M, Glatzel G, Tadesse Y. Tree species screened on nitosols of central ethiopia: biomass production, nutrient contents and effect on soil nitrogen. Journal of Tropical Forest Science. 2006;18(3):173-180.

13. Gomez KA, Gomez AA. Statistical Procedures for Agricultural Research. 2nd ed. John Wiley and Sons, New York; 1984.

14. Geist HJ, Lambin EF. Proximate causes and underlying drivingforces of tropical deforestation. BioScience. 2002;52(2):143-150.

15. Hiemstra HG, Hovorka AJ. Fuelwood: The "other"renewable energy source for Africa?. Biomass and Bioenergy. 2009;33 (11):1605-1616.

16. Chazdon RL. Beyond deforestation: restoring forests and ecosystemservices on degraded lands. Science. 2008; 320(5882):1458-1460.

17. Yirdaw E, Luukkanen O. Indigenous woody species diversityin eucalyptus globuluslabill. ssp. globulus plantations inthe ethiopian highlands. Biodiversity and Conservation. 2003;12(3):567-582.

18. Mekonnen K, Tadesse Y, Gerhard G, et al. Performance of eighttree species in the highland vertisols of central Ethiopia: growth, foliagenutrient concentration and effect on soil chemical properties. New Forests. 2006;32(3):285-98.

19. Peter D, Erskine D, Geoff B. Growth performance and man-agement of a mixed rainforest tree plantation. New Forests. 2005; 29(2):117-134.

20. Arredondo S, Aronson J, Ovalle C, et al. Screeningmultipurpose legume trees in central Chile. Forest Ecology and Management. 1998;109(13):221-229.

21. WEC. The challenge of rural energy poverty in developing countries. FAO, World Energy Council. UK; 1999.

22. Wood PJ, Burley J. A Tree for all Reasons: the Introduction and evaluation of multipurpose trees for agroforestr y. ICRAF, Nairobi; 1991. 